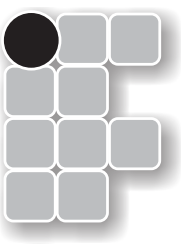

\title{
ESTERCO DE COELHO: FONTE DE NUTRIENTES PARA COMPLEMENTAÇÃO DA ADUBAÇÃO
}

Carla Regina Amorim dos Anjos Queiroz

Reginaldo Rodrigues de Andrade ${ }^{2}$

Zilda Corrêa de Lacerda ${ }^{3}$

Manoel Evaristo Ferreira ${ }^{4}$

\section{Resumo}

Os resíduos ou adubos orgânicos aplicados ao solo são fontes de matéria orgânica que promovem melhoria em propriedades físicas e químicas do solo, aumentando a sua capacidade produtiva. Objetivouse avaliar a influência do esterco de coelho, combinado ou não com adubo industrial ${ }^{5}$, em milheto. 0 experimento foi conduzido em vasos, em ambiente protegido, e o delineamento experimental foi 0 inteiramente casualizado com oito tratamentos e cinco repetições. Os resultados mostraram que o uso concomitante de adubo industrial e de esterco de coelho promoveu aumento do perfilhamento, da altura de plantas e produção de massa seca de milheto. Houve aumento na produção de massa seca quando adubo industrial (nas doses $40 \mathrm{~kg} \mathrm{ha}^{-1} \mathrm{~N}, 400 \mathrm{~kg} \mathrm{ha}^{-1} \mathrm{P}_{2} \mathrm{O}_{5}$ e $50 \mathrm{~kg} \mathrm{ha}^{-1} \mathrm{~K}_{2} \mathrm{O}$ ) foi combinado com esterco de coelho, até a dose de $21,7 \mathrm{t} \mathrm{ha}^{-1}$.

Palavras-chave: Adubação orgânica. Cultivo protegido. Milheto.

\section{Introdução}

Os resíduos orgânicos, vegetais ou animais, gerados pelas atividades agropecuárias são importantes fontes de biomassa (ORRICO et al., 2007) que podem ser reintegradas na cadeia produtiva pela incorporação ao solo, agregando valores econômicos e ambientais à produção, pelo menor gasto de insumos industriais (LOSS et al., 2009) pois favorece a fertilidade do solo liberando nutrientes durante 0 ciclo das culturas (SEDIYAMA et al., 2009).

Os estercos de gado, aves, suíno, caprino e coelho são fontes de matéria orgânica, favorecem a melhoria dos atributos químicos, físicos e biológicos do solo e podem ser fonte de nutrientes (MORAL et al., 2005), tanto se usados separadamente (NICOLAU SOBRINHO et al., 2009) quanto na composição de substratos com adubos industriais (SILVA et al., 1999; SILVA; CAMARGO; CERETTA, 2010; SILVA et al., 2011) ou mesmo com outras fontes vegetais (SANTI et al., 2010; SERRANO; SILVA; FORMENTINI, 2011).

Azeez, Averbeke e Okorogbona (2010) consideram limitado o conhecimento acerca da resposta das culturas à aplicação de diferentes tipos de esterco, embora seu uso seja bastante difundido, porém, foram observados aumentos da produção de figueiras (LEONEL; TECCHIO, 2009), de milho (SAMPAIO et al., 2007) e de milheto (NICOLAU SOBRINHO et al., 2009). O efeito do esterco foi maior do que o de adubo industrial em milho (SILVA et al., 2011); suficiente para fornecer nutrientes, na ausência de adubo industrial, para produção de mudas de mamoeiro (CANESIN; CORRÊA, 2006) e para o fornecimento de $N$ para alface (SILVA et al., 2010). Para produção de mudas de guanandi foi considerado desnecessário a

${ }^{1}$ Instituto Federal do Triângulo Mineiro, professora. Uberlândia, Minas Gerais, Brasil. carlaregina@iftm.edu.br. (034) 3233-8851. Fazenda Sobradinho, s.n. ${ }^{\circ}$, Zona Rural, Uberlândia (MG). CEP: 38400-970, Caixa Postal 1020.

${ }^{2}$ Instituto Federal do Triângulo Mineiro, professor. Uberlândia, Minas Gerais, Brasil. reginaldoandrade@iftm.edu.br. (034) 3233-8868. Fazenda Sobradinho, s.n. ${ }^{\circ}$, Zona Rural, Uberlândia (MG). CEP: 38400-970, Caixa Postal 1020.

${ }^{3}$ Instituto Federal do Triângulo Mineiro, professora. Uberlândia, Minas Gerais, Brasil. zilda@iftm.edu.br. (034) 3233-8851. Fazenda Sobradinho, s/n, Zona Rural, Uberlândia (MG). CEP: 38400-970, Caixa Postal 1020.

${ }^{4}$ Universidade Estadual Paulista Júlio de Mesquita Filho, professor pesquisador, Jaboticabal, São Paulo, Brasil. evaristo@fcav.unesp.br. Via de

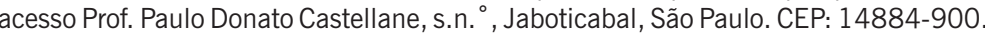

${ }^{5}$ Neste trabalho o termo "adubo industrial" refere-se aos adubos sintéticos, fontes de N, P e K na forma mineral e orgânica, produzidos industrialmente. 
complementação com adubo industrial (ARTUR et al., 2007), em função do crescimento de espécies climácicas serem de baixa exigência em relação à disponibilidade de nutrientes no solo.

O uso de fontes orgânicas de nutrientes, combinado a fontes industriais, maximizou a produção, aumentando a eficiência da adubação orgânica em batatas (FIOREZE; CERETTA, 2006), amendoim (BASU et al., 2008), pimentão (SEDIYAMA et al., 2009) e em mamoneira (SEVERINO et al., 2006).

O esterco de coelho apresenta composição média de 1,5 a 2,5\% de N, 1,4 a 1,8\% de P e 0,5 a 0,8\% de K (MACHADO; FERREIRA, 2011). A composição média de N no esterco de coelho assemelha-se aos teores encontrados em estercos de bovino $(2,08 \% ; 2,27 \%)$, e é um pouco inferior aos estercos de suíno $(2,74 \% ; 3,18 \%)$ e galinha $(4,03 \% ; 3,11 \%)$ (CHACÓN, 2005; RAIJ et al., 1997).

$O$ esterco de coelho apresenta teores de $P$ que podem ser menores ou maiores que o presente em estercos de outras fontes, tal como citado por Raij et al. (1997) e Chacón (2005) para esterco de galinhas $(1,78 \%$ e $1,95 \%)$, bovinos $(1,8 \%$ e $0,75 \%)$ e suínos $(0,9 \%$ e $1,45 \%)$. As diferenças nos teores apresentados indicam que há variabilidade de teores de nutrientes em função dos animais e dos tratamentos a que cada plantel foi submetido, as quais podem ser a causa de respostas diferenciadas de vegetais frente à aplicação de estercos (AZEEZ; AVERBEKE; OKOROGBONA, 2010).

Em estudo de caracterização, decomposição e biodisponibilidade de materiais orgânicos, Chacón (2005) verificou que o esterco de coelho in natura apresenta pequena fração de fácil biodegradação (C/N $=21$ ) se comparado ao esterco de suíno ou de aves $(\mathrm{C} / \mathrm{N}=18$ e 9 , respectivamente) e pequena imobilização.

O milheto (Pennisetum americanum) é uma planta forrageira de ciclo anual que vem sendo estudada para o uso como fonte complementar da alimentação de gado de corte tanto sob pastejo quanto sob a forma de grãos como fonte de energia. É uma espécie bem adaptada a regiões semiáridas e no Brasil, a região Centro-Oeste se destaca na utilização do grão do milheto. Ele tem características nutritivas e agronômicas que permitem que ele seja usado como fonte energética para alimentação animal (RIBEIRO, 2004), e foi usado como planta-teste neste trabalho.

Objetivou-se avaliar a influência do esterco de coelho, combinado ou não com adubo industrial, no crescimento de plantas de milheto.

\section{Material e métodos}

O experimento foi conduzido em ambiente protegido no Instituto Federal de Educação, Ciência e Tecnologia do Triângulo Mineiro (IFTM), Campus Uberlândia (MG) (altitude de $633 \mathrm{~m}$, latitude $18^{\circ} 45^{\prime}$ 47,9" S e longitude 48 17'20,1" W), no ano de 2009. A cobertura foi de plástico com espessura de $150 \mathrm{~m}$ e as laterais, de tela sombrite com $50 \%$ de redução da luminosidade. 0 delineamento experimental foi 0 inteiramente casualizado, com oito tratamentos: Testemunha $\left(T_{1}\right)$ sem adubação; $0\left(T_{2}\right), 5\left(T_{3}\right), 10\left(T_{4}\right), 15$ $\left(T_{5}\right), 20\left(T_{6}\right)$ e $25\left(T_{7}\right) t$ ha $^{-1}$, respectivamente, de esterco de coelho associadas a doses fixas de adubo industrial ( $\mathrm{N}=40 \mathrm{~kg} \mathrm{ha}^{-1}$, na forma de ureia; $\mathrm{P}_{2} \mathrm{O}_{5}=400 \mathrm{~kg} \mathrm{ha}^{-1}$ na forma de superfosfato simples e $\mathrm{K}_{2} \mathrm{O}=$ $50 \mathrm{~kg} \mathrm{ha}^{-1}$ como KCl) e um tratamento com $15 \mathrm{t} \mathrm{ha}^{-1}$ de esterco na ausência de adubo industrial $\left(\mathrm{T}_{8}\right.$ ) e cinco repetições.

O esterco de coelho usado no experimento foi produzido pelo plantel do IFTM - Campus Uberlândia, e sua composição de macronutrientes e carbono, em $\mathrm{g} \mathrm{kg}^{-1}$ : $\mathrm{N}=13,8 ; \mathrm{K}=19,4 ; \mathrm{P}=31,1$; $\mathrm{Ca}=43$,6; $\mathrm{S}$ $=1,2 ; \mathrm{Mg}=9,0 ; \mathrm{C}_{\text {orgânico }}=218,4 ; \mathrm{C}_{\text {total }}=291,1$. Em relação aos micronutrientes, em mg kg-1: $\mathrm{Zn}=$ 819,0; $\mathrm{Na}=2125,0 ; \mathrm{B}=19,0 ; \mathrm{Cu}=122,0 ; \mathrm{Mn}=605,0$ e $\mathrm{Fe}=9802,0$. As relações carbono/nitrogênio $(\mathrm{C} / \mathrm{N})$, carbono/enxofre $(\mathrm{C} / \mathrm{S})$ e carbono/fósforo $(\mathrm{C} / \mathrm{P})$ foram respectivamente 21,1 , 242,6 e 9,4 .

O solo utilizado foi coletado na camada de 0-20 cm em área com vegetação de cerrado, na periferia da cidade de Uberlândia (MG), seco a sombra e passado em peneira com malha de $4 \mathrm{~mm}$. Foram retiradas amostras para análises granulométrica e química, realizadas, respectivamente, no Laboratório de Manejo de Solos (LAMAS) e Laboratório de Fertilidade de Solos (LABAS), ambos na Universidade Federal de Uberlândia, de acordo com método descrito por EMBRAPA (1999). O solo foi classificado como muito argiloso (areia grossa $=60 \mathrm{~g} \mathrm{~kg}^{-1}$; areia fina $=72 \mathrm{~g} \mathrm{~kg}^{-1}$; silte $=78 \mathrm{~g} \mathrm{~kg}^{-1}$ e argila $=790 \mathrm{~g} \mathrm{~kg}^{-1}$ ) e os atributos químicos apresentados foram: $\mathrm{pH}_{\mathrm{H}^{2} \mathrm{O}}=5,0 ; \mathrm{Al}^{3+}=0,5 \mathrm{cmol}_{\mathrm{c}} \mathrm{dm}^{-3} ; \mathrm{H}+\mathrm{Al}=4,9 \mathrm{cmol}_{\mathrm{c}}$ $\mathrm{dm}^{-3} ; \mathrm{P}=1,4 \mathrm{mg} \mathrm{dm}^{-3} ; \mathrm{K}^{+}=0,08 \mathrm{cmol}_{\mathrm{c}} \mathrm{dm}^{-3} ; \mathrm{Ca}^{2+}=0,3 \mathrm{cmol}_{\mathrm{c}} \mathrm{dm}^{-3} ; \mathrm{Mg}^{2+}=0,1 \mathrm{cmol}_{\mathrm{c}} \mathrm{dm}^{-3} ; \mathrm{V}^{2}$ $=9$ e 2,9 dag kg-1 de matéria orgânica. 
Para correção da acidez do solo usou-se calcário dolomítico com 18\% de CaO, 16\% de MgO e poder relativo de neutralização total (PRNT) de 98\%. A calagem foi feita por repetição, com adição de 5,1 g de calcário à $3,1 \mathrm{dm}^{3}$ de solo, em sacos de plástico individuais, com agitação para homogeneização. Após a calagem, foram acrescentados $850 \mathrm{~mL}$ de água a cada saco e, após mistura da mesma ao solo, os sacos foram fechados, tomando-se o cuidado de deixar orifícios para as trocas gasosas, permanecendo sob incubação por um período de dez dias.

Após calagem e secagem, a análise química do solo apresentou $\mathrm{pH}_{\mathrm{H} 2 \mathrm{O}}=5,6 ; \mathrm{Al}^{3+}=0,0 \mathrm{cmol}_{\mathrm{c}} \mathrm{dm}^{-3}$; $\mathrm{H}+\mathrm{Al}=3,1 \mathrm{cmol}_{\mathrm{c}} \mathrm{dm}^{-3} ; \mathrm{P}=2,0 \mathrm{mg} \mathrm{dm}^{-3} ; \mathrm{K}^{+}=0,10 \mathrm{cmol}_{\mathrm{c}} \mathrm{dm}^{-3} ; \mathrm{Ca}^{2+}=1,2 \mathrm{cmol}_{\mathrm{c}} \mathrm{dm}^{-3} ; \mathrm{Mg}^{2+}=0,4 \mathrm{cmol}_{\mathrm{c}}$ $\mathrm{dm}^{-3} ; \mathrm{V} \%=35$.

Pesaram-se porções equivalentes a $2,8 \mathrm{dm}^{3}$ de solo, que foram colocadas em sacos de plástico individualizados, onde receberam o fósforo e o esterco de coelho. Em seguida o conteúdo de cada saco foi misturado. Após homogeneização, o conteúdo de cada saco foi transferido para vasos de alumínio com capacidade para $3,1 \mathrm{dm}^{3}$, com furo no fundo para escoar excesso de água e a parede interna pintada com neutrol para protegê-lo contra corrosão. Em cada vaso previamente identificado, com borda livre de $2 \mathrm{~cm}$, foram adicionados sobre o solo $100 \mathrm{~mL}$ de solução contendo a dose total de potássio e a metade da dose de nitrogênio.

A semeadura foi feita no dia $1^{\circ}$ de maio de 2009 , com semente de milheto, com $95 \%$ de pureza. Foram semeadas dez sementes por vaso, a cerca de $1 \mathrm{~cm}$ de profundidade. A emergência das plântulas ocorreu entre quatro e cinco dias após a semeadura (DAS) e o desbaste, deixando cinco plantas por vaso, foi feito dez dias após o semeio. A segunda metade da dose de nitrogênio e a aplicação de Deltametrina $\left(0,75 \mathrm{~g} \mathrm{~L}^{-1}\right)$ para controle de pulgão, ocorreram, respectivamente, aos 15 e 25 DAS. Durante a condução do experimento os vasos foram rotacionados e trocados de posição para minimizar efeitos de diferenças na luminosidade, vento e competição entre plantas. A verificação da perda de água nos vasos foi feita por meio da pesagem dos vasos e obtida por diferença de massa. Na reposição foi utilizada água deionizada durante todo experimento.

Aos 41 dias após a emergência, foram feitas medidas da altura das plantas e contagem do número de perfilhos. Logo a seguir, a parte aérea das plantas de cada vaso foi cortada, lavada com água corrente, transferida para embalagens de papel e levada para estufa com circulação forçada de ar a $65^{\circ} \mathrm{C}$, onde foi seca até massa constante.

Todos os dados foram tratados estatisticamente pelo teste $\mathrm{F}$ de variância, teste de comparação de médias de Tukey e análise de regressão para as doses testadas. Os dados relativos ao número de perfilhos foram analisados com transformação em $\sqrt{x+1}$

\section{Resultados e discussão}

O esterco de coelho apresentou potencial para mineralização em curto prazo, em função das relações $\mathrm{C} / \mathrm{P}$ e $\mathrm{C} / \mathrm{S}$ abaixo dos valores estabelecidos como indicadores ( $\mathrm{C} / \mathrm{P} \leq 200 \mathrm{e} \mathrm{C} / \mathrm{S} \leq 300$ ), além de relação $\mathrm{C} / \mathrm{N}$ próxima do valor indicado como referência $(\mathrm{C} / \mathrm{N} \leq 20)$ podendo ser classificado como um fertilizante orgânico simples de acordo com o decreto 4954/2004 (BRASIL, 2004) e em conformidade com a Instrução Normativa n. ${ }^{\circ}$ 25/2009 do Ministério da Agricultura (BRASIL, 2009).

A adubação, somente com adubo industrial $\left(T_{2}\right)$ ou somente com esterco de coelho $\left(T_{8}\right)$, assim como suas combinações $\left(T_{3}-T_{7}\right)$, promoveu aumento da altura, do número de perfilhos e da massa seca das plantas de milheto ( $p<0,01$, Tabela 1 ). A adubação industrial ( $N, P$ e K) associada ao esterco de coelho aumentou o crescimento das plantas, medido pela altura, mas a diferença só ocorreu entre as plantas adubadas $\left(\mathrm{T}_{2}\right.$ ao $\left.\mathrm{T}_{8}\right)$ e não adubada $\left(\mathrm{T}_{1}\right)$.

$O$ efeito da adubação com adubo industrial associada à adubação orgânica $\left(T_{4}\right.$ ao $\left.T_{7}\right)$ sobre a produção de matéria seca (Tabela 1 ) foi, em média, mais pronunciado e o resultado foi maior tanto em relação à adubação industrial sem esterco de coelho $\left(T_{2}\right)$ quanto em relação à adubação exclusiva com esterco de coelho $\left(\mathrm{T}_{8}\right)$. Isto indica o efeito benéfico do conjunto adubação industrial e orgânica, como observado para o cultivo de abóbora (Cucurbita maxima L.) e erva-moura (Solanum retroflexum Dun.) com estercos de aves, caprinos e gado (AZEEZ et al., 2010), de amendoim (BASU et al., 2008) e de soja (HATI et al., 2006). É possível que a combinação adubo industrial e esterco de coelho tenha favorecido tanto a oferta de nutrientes quanto a melhoria dos atributos físicos, químicos e biológicos do solo, como 
aumento da aeração, da permeabilidade e da capacidade de retenção da água, melhora do poder tamponante, além de regular a disponibilidade de micronutrientes e atividade enzimática (SILVA; CAMARGO; CERETTA, 2010).

Tabela 1: Médias de altura, número de perfilhos e massa seca de plantas de milheto aos 41 dias após semeio e resumo da análise de variância, Uberlândia (MG), 2009.

\begin{tabular}{|c|c|c|c|}
\hline $\begin{array}{c}\text { Esterco de coelho } \\
\left(\mathrm{t} \mathrm{ha}^{-1}\right)\end{array}$ & $\begin{array}{c}\text { Altura } \\
(\mathrm{cm})\end{array}$ & $\begin{array}{c}\text { Perfilhos } \\
\text { (uni dades vaso } \\
\end{array}$ & $\begin{array}{l}\text { Massa seca } \\
\left(\text { g vaso }^{-1}\right) \\
\end{array}$ \\
\hline $\mathrm{T}_{1}-0^{\#}$ & $9,0 \pm 2,0 \mathrm{~b}$ & $0,0 \pm 0,0 c$ & $1,16 \pm 0,12 \mathrm{e}$ \\
\hline $\mathrm{T}_{2}-0$ & $65,7 \pm 10,6 a$ & $7,8 \pm 1,6 a$ & $19,00 \pm 0,58 d$ \\
\hline T3- 5 & $79,0 \pm 13,4 a$ & $7,0 \pm 1,2 \mathrm{ab}$ & $22,13 \pm 1,52 b c$ \\
\hline $\mathrm{T}_{4}-10$ & $79,6 \pm 10,9 a$ & $7,8 \pm 1,3 a$ & $24,26 \pm 1,15 a b$ \\
\hline T5- 15 & $78,9 \pm 9,2 \quad a$ & $9,0 \pm 1,6 a$ & $25,67 \pm 0,94 a$ \\
\hline T $6-20$ & $65,7 \pm 11,4 a$ & $8,2 \pm 1,3 a$ & $25,83 \pm 2,04 a$ \\
\hline$T 7-25$ & $69,2 \pm 9,8 \quad a$ & $9,8 \pm 1,5 a$ & $26,26 \pm 1,13$ a \\
\hline T $8-15^{\#}$ & $88,1 \pm 14,3 a$ & $4,8 \pm 1,6 b$ & $20,60 \pm 2,14 \mathrm{~cd}$ \\
\hline \multicolumn{4}{|c|}{ Resumo análise variância } \\
\hline Quadrado médio & 2563,9703 & $2,7041_{\star \star}$ & 343,6526 \\
\hline "F" & $117,15^{* *}$ & $47,69^{\star \star}$ & $184,50^{* \star}$ \\
\hline Resíduo & 32 & 32 & 32 \\
\hline CV (\%) & 7,2 & 8,8 & 6,6 \\
\hline
\end{tabular}

"Sem adição de adubo industrial; Médias seguidas por letras distintas na vertical diferem entre si ao nível de 5\% de probabilidade pelo teste de Tukey; CV = coeficiente de variação; valores após sinal de \pm referem-se ao desvio padrão.

Fonte: Elaboração dos autores

Embora a produção de massa seca em folhas de milheto tenha sido menor no tratamento adubado unicamente com esterco de coelho (T8) quando comparado com os tratamentos em que se combinou adubação industrial com e esterco de coelho, destaca-se que a produção foi igual ao tratamento adubado exclusivamente com adubo industrial $\left(\mathrm{T}_{2}\right)$ (Tabela 1 ), o que pressupõe rápida mineralização dos nutrientes presentes no esterco de coelho na forma orgânica, quando estes formaram o substrato de plantio, conforme também verificado por Chacón (2005). Além disso, segundo Fageria (1998) a presença de matéria orgânica favorece vários aspectos do desenvolvimento das culturas, em função de aumentar a capacidade de absorção de cátions, de retenção de água, estabilizar a temperatura do solo e melhorar a granulação do solo, o que poderia justificar o maior ganho de massa nas plantas de milheto na presença do esterco de coelho. Segundo Silva et al. (1999) o efeito positivo da presença de matéria orgânica no crescimento de plantas, tanto em parte aérea quando em raízes, está relacionado com o aumento da absorção de nutrientes minerais.

Não houve perfilhamento no tratamento sem adubação mineral e sem esterco de coelho $\left(T_{1}\right)$, e, entre os tratamentos com adubação industrial, houve, em média, a produção de 8,3 perfilhos vaso ${ }^{-1}$, independentemente da dose de esterco $\left(T_{2}\right.$ a $\left.T_{7}\right)$. A adubação com esterco de coelho sem adubação industrial $\left(\mathrm{T}_{8}\right)$ produziu menos perfilhos $\left(4,8\right.$ perfilhos vaso $\left.{ }^{-1}\right)$ do que naqueles tratamentos com adubação combinada (Tabela 1). No tratamento sem adubação (com adubo industrial ou esterco) (Testemunha, $\mathrm{T}_{1}$ ) os resultados para os atributos avaliados foram inferiores aos demais tratamentos, refletindo em crescimento limitado devido à ausência de quantidades adequadas de nutrientes.

Entre os tratamentos que receberam esterco de coelho e adubo industrial $\left(T_{2}\right.$ a $\left.T_{7}\right)$, a análise de variância da regressão evidenciou efeito significativo $(p<0,01)$ na produção de massa seca, com ajuste da regressão quadrático também significativo $(p<0,01)$. Para a altura e o número de perfilhos das plantas, a análise da variância da regressão foi não significativa $(p>0,05)$ (Tabela 2). 
Tabela 2: Resumo da análise da variância da regressão dos tratamentos com adubo industrial e doses de esterco de coelho, em relação à altura, número de perfilhos e massa seca de folhas.

\begin{tabular}{lccc}
\hline Regressão polinomial entre doses de esterco & \multicolumn{3}{c}{ Atributos } \\
\cline { 2 - 4 } de coelho com adubo industrial $\left(\mathrm{T}_{2}-\mathrm{T}_{7}\right)$ & Altura & Perfilhos & Massa seca \\
\hline "F" da análise de variância entre as doses & $1,6417^{\mathrm{NS}}$ & $2,4032^{\mathrm{NS}}$ & $23,1093^{* *}$ \\
"F" da análise de variância da regressão & - & - & $15,7931^{* *, \mathrm{x}}$ \\
Resíduo & 24 & 24 & 24 \\
CV (\%) & 7,0 & 7,7 & 5,5 \\
\hline
\end{tabular}

${ }^{(* *)}$ significativo a $1 \%$ de probabilidade, ${ }^{(\text {NS) }}$ não significativo, ${ }^{(x)}$ do maior grau significativo para regressão polinomial (grau 2).

Fonte: Elaboração dos autores.

Em função das doses de esterco de coelho houve aumento da massa seca de folhas de milheto (Figura 1), com produção máxima de 26,3 g por vaso, estimada com aplicação de 21,7 t ha ${ }^{-1}$ de esterco. Essa produção corresponde a um aumento de 37,7\% (cerca de 7,2 g) em relação ao tratamento sem esterco $\left(T_{2}, 0\right.$ t ha $\left.^{-1}\right)$. A produção máxima de massa seca obtida com 21,7 t ha $^{-1}$ é igual (diferença de $0,6 \%$ ) a produção com a maior dose de esterco $\left(25 \mathrm{t} \mathrm{ha}^{-1}\right)$.

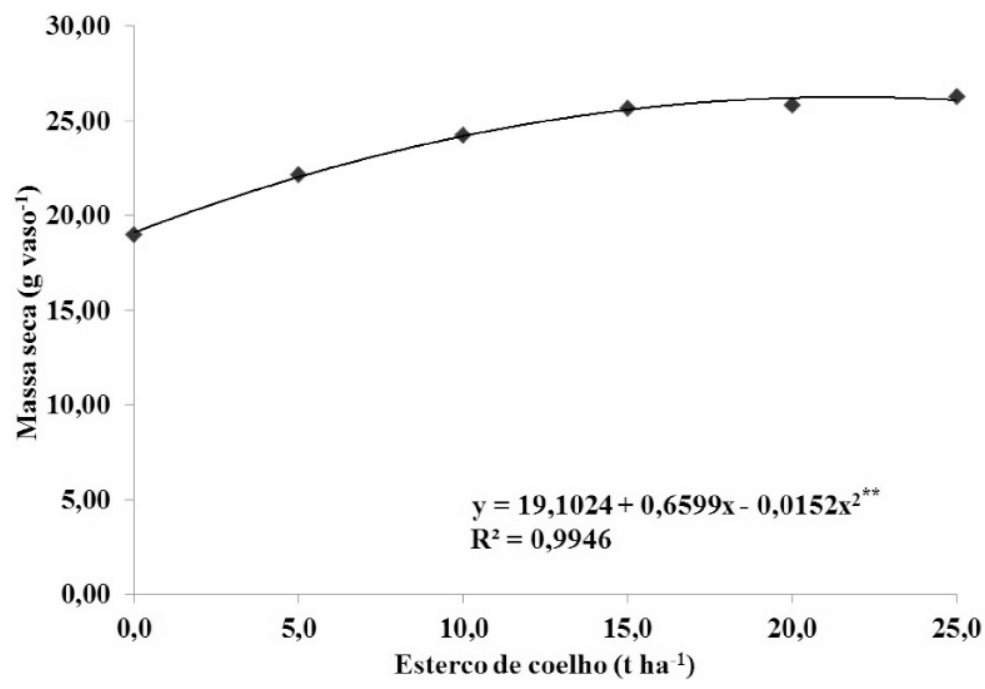

Figura 1: Massa seca média do milheto em função das doses de esterco de coelho, aos 41 dias após semeadura.

Fonte: Elaboração dos autores

A análise de variância dos resultados para altura das plantas e número de perfilhos (Tabela 1) indica que doses de esterco de coelho de 10 a $25 \mathrm{t} \mathrm{ha}^{-1}$ influenciaram positiva e igualmente a resposta das plantas de milheto. Se considerada também a massa seca produzida, entretanto, a dose de esterco de coelho mais eficiente está em torno de 21,7 t ha ${ }^{-1}$ (Figura 1). Resposta obtida em modelo matemático quadrático com ponto de máxima produção também foi observada em estudo com milho, Silva et al. (1999) em relação à produção de folhas secas com uso de cama de frango em torno de 21 t ha ${ }^{-1}$ e em avaliação de massa seca de folhas, ramos, raízes e total em cafeeiros conilon (SERRANO; SILVA; FORMENTINI, 2011). Esses resultados apontam para efeitos positivos na absorção de nutrientes até a dose máxima, a partir da qual seriam observados efeitos negativos (SILVA et al., 1999).

\section{Conclusão} de coelho.

Houve aumento na produção de massa seca quando o adubo industrial foi combinado com esterco 


\section{Rabbit manure: nutrient source complement for fertilization}

\section{Abstract}

Wastes or organic fertilizers applied to the soil are sources of organic matter that promotes improvement in physical and chemical properties of the soil, increasing its production capacity. This study aimed to assess the efficacy of rabbit manure, combined or not with industrial fertilizer in millet. The experiment was conducted in pots under greenhouse conditions, and the experimental design was a completely randomized with 5 treatments and 8 replications. The results showed that concomitant use of industrial fertilizer and manure rabbit promoted increased tillering, plant height and dry matter production of millet. There was an increase in dry matter production when industrial fertilizer (at doses $40 \mathrm{~kg} \mathrm{ha}^{-1} \mathrm{~N}$, $400 \mathrm{~kg} \mathrm{ha}^{-1} \mathrm{P}_{2} \mathrm{O}_{5}$ and $50 \mathrm{~kg} \mathrm{~K}_{2} \mathrm{O} \mathrm{ha}{ }^{-1}$ ) was combined with rabbit manure, up to a dose of $21.7 \mathrm{tha}^{-1}$.

Key words: Millet. Organic fertilization. Protected cultivation.

\section{Referências Bibliográficas}

ARTUR, A. G. et al. Esterco bovino e calagem para formação de mudas de guanandi. Pesquisa Agropecuária Brasileira, Brasília, v. 42, n. 6, p. 843-850, jun. 2007.

AZEEZ, J. O.; AVERBEKE, W. V.; OKOROGBONA, A. O. M. Differential responses in yield of pumpkin (Curcubita maxima L.) and night shade (Solaum retroflexum Dun.) to the aplication of three animal manures. Bioresource Technology, Nova lorque, v. 101, n. 7, p. 2499-2505, abr. 2010.

BASU, M.; BHADORIA, P. B. S.; MAHAPATRA, S. C. Growth, nitrogen fixation, yield and kermel quality of peanut in response to lime, organic and inorganic fertilizer levels. Bioresource Technology, Nova lorque, v. 99, n. 11, p. 4675-4683, julho, 2008.

BRASIL. Ministério da Agricultura Pecuária e Abastecimento. Decreto n. ${ }^{\circ} 4.954$ de 14 de janeiro de 2004. Dispõe sobre a inspeção e fiscalização da produção e do comércio de fertilizantes, corretivos, inoculantes ou biofertilizantes destinados à agricultura. Diário Oficial [da] República Federativa do Brasil, Brasília (DF), 15 janeiro 2004.

. Ministério da Agricultura Pecuária e Abastecimento. Instrução Normativa SDA n. ${ }^{\circ} 25$ de 23 de julho de 2009. Normas sobre as especificações e as garantias, as tolerâncias, o registro, a embalagem e a rotulagem dos fertilizantes orgânicos simples, mistos, compostos, organominerais e biofertilizantes destinados à agricultura. Diário Oficial [da] República Federativa do Brasil, Brasília (DF), 28 julho 2009.

CANESIN, R. C. F. S.; CORRÊA, L. D. S. Uso de esterco associado à adubação mineral na produção de mudas de mamoeiro (Caricapapaya L.). Revista Brasileira de Fruticultura, Jaboticabal, v. 28, n. 3, p. 481-486, dez., 2006.

CHACÓN, E. A. V. Caracterização, decomposição e biodisponibilidade de nitrogênio e fósforo de materiais orgânicos de origem animal e vegetal. 2005. 143 f. Tese. (Doutorado em Solos e Nutrição de Plantas). Universidade Federal de Viçosa, Viçosa (MG).

EMPRESA BRASILEIRA DE AGROPECUÁRIA. Manual de análises químicas de solos, plantas e fertilizantes. Brasília (DF): EMBRAPA, 1999. 370 p.

FAGERIA, N. K. Otimização e eficiência nutricional na produção das culturas. Revista Brasileira de Engenharia Agrícola e Ambiental, Campina Grande, v. 2, p. 6-16, 1998.

FIOREZE, C.; CERETTA, C. A. Fontes orgânicas de nutrientes em sistemas de produção de batata. Revista Ciência Rural, Santa Maria, v. 36, n. 6, p. 1788-1793, nov.-dez., 2006.

HATI, K. M. et al. Effect of inorganic fertilizer and farmyard manure on soil physical properties, root distribution, and water-use efficiency of soybean in Vertisols of central India. Bioresource Technology, Nova lorque, v. 97, n. 
LEONEL, S.; TECCHIO, M. A. Cattle manure fertilization increases fig yield. Sciencia Agricola, Piracicaba, v. 66, n. 6, p. 806-811, nov./dez., 2009.

LOSS, A. et al. Distribuição dos agregados e carbono orgânico influenciados por manejos agroecológicos. Acta Scientiarum. Agronomy. Maringá, v. 31, n. 3, p. 523-528, 2009.

MACHADO, L. C.; FERREIRA, W. M. A cunicultura e o desenvolvimento sustentável. Associação Científica B ra s i l e i ra d e C un i cultura, 2011 . Dis ponível e m : <http://www.acbc.org.br/cuniculturaedesenvolvimentosustentavel.pdf>. Acesso em: 21 jun. 2012.

MORAL, R. et al. Characterization of the organic matter pool in manures. Bioresource Technology, Nova lorque, v. 96, n. 2, p. 153-158, janeiro, 2005.

NICOLAU SOBRINHO, W. et al. S. Acúmulo de nutrientes nas plantas de milheto em função da adubação orgânica e mineral. Revista Caatinga, Mossoró, v. 22, n. 3, p. 107-110, 2009.

ORRICO, A. C. A.; LUCAS JÚNIOR, J. de.; ORRICO JÚNIOR, M. A. P. Caracterização e biodigestão anaeróbia de caprinos. Engenharia Agrícola, Jaboticabal, v. 23, n. 3, p. 639-647, set.-dez., 2007.

RAIJ, B. VAN et al. Recomendações de adubação e calagem para o Estado de São Paulo. 2. ed. Campinas (SP): Fundação IAC, v. 1, 1997. Boletim Técnico n. 100.

RIBEIRO, C. V. Di M. et al. Substituição do Grão de Milho pelo Milheto (Pennisetum americanum) na Dieta de Vacas Holandesas em Lactação. Revista Brasileira de Zootecnia, Viçosa (MG), v. 33, n. 5, p.1351-1359, 2004.

SAMPAIO, E. V. D. S. B.; OLIVEIRA, N. M. B. D.; NASCIMENTO, P. R. F. D. Eficiência da adubação orgânica com esterco bovino e com Egeria densa. Revista Brasileira de Ciência do Solo, Viçosa, v. 31, n. 5, p. 995-1002, set.-out., 2007.

SANTI, A. et al. Ação de material orgânico sobre a produção e características comerciais de cultivares de alface. Horticultura Brasileira, Vitória da Conquista, v. 28, n. 1, p. 87-90, jan.-mar., 2010.

SEDIYAMA, M. A. N. et al. Rendimento de pimentão em função da adubação orgânica e mineral. Horticultura Brasileira, Vitória da Conquista, v. 27, p. 294-299, set., 2009.

SERRANO, L. A. L.; SILVA, V. M. da; FORMENTINI, E. A. Uso de compostos orgânicos no plantio do cafeeiro conilon. Revista Ceres, Viçosa, v. 58, n.1, p. 100-107, jan.-fev., 2011.

SEVERINO, L. S. et al. Produtividade e crescimento da mamoneira em resposta à adubação orgânica e mineral. Pesquisa Agropecuária Brasileira, Brasília, v. 411, n. 5, p. 879-882, maio, 2006.

SILVA, L. S.; CAMARGO, F. A. D. O.; CERETTA, C. A. Composição da fase sólida orgânica do solo. In: MEURER, E. J. Fundamentos de Química do Solo. 4. ed. Porto Alegre: Evangraf, 2010. Cap. 3, p. 59-83.

SILVA, N. F. et al. Crescimento e estado nutricional de abóbora híbrida em função de adubação orgânica e mineral. Horticultura Brasileira, Brasília, v. 17, n. 3, p. 193-200, nov., 1999.

SILVA, T. R. da et al. Cultivo de milho e disponibilidade de P sob adubação com cama-de-frango. Revista Brasileira de Engenharia Agrícola e Ambiental, Campina Grande, v. 15, n. 9, p. 903-910, set., 2011.

SILVA, F. A. D. M.; BÔAS, R. L. V.; SILVA, R. B. Resposta da alface à adubação nitrogenada com diferentes compostos orgânicos em dois ciclos sucessivos. Acta Scientiarum. Agronomy, Maringá, v. 32, n. 1, p. 131137, jan.-mar., 2010. 


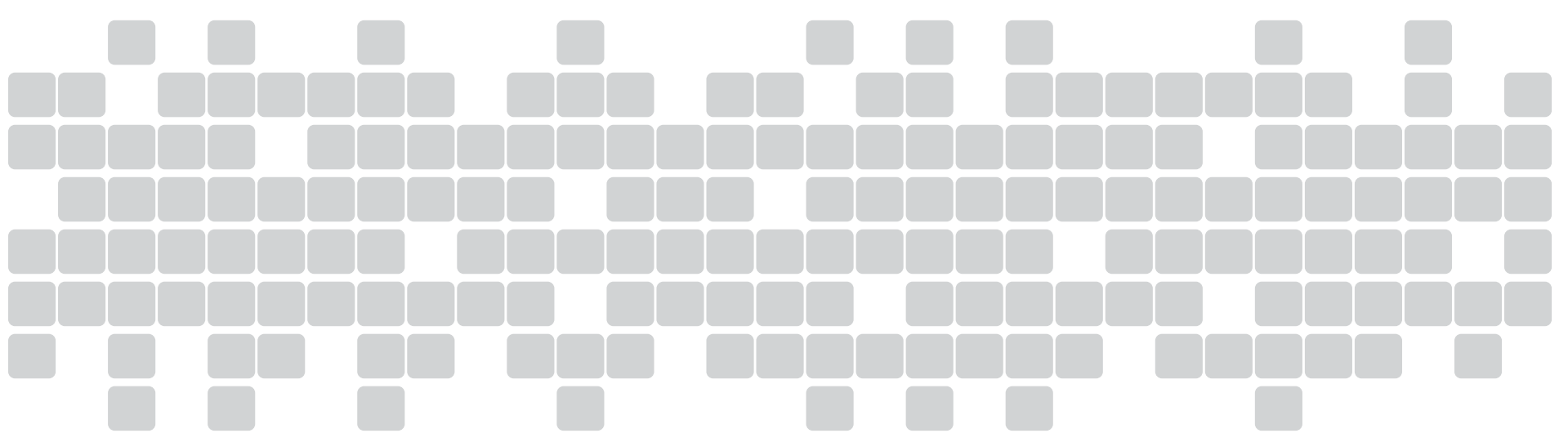

